\title{
ALGUNOS TEMAS DE «NIETZSCHE COMO EDUCADOR»
}

\author{
Some issues of «Nietzsche as educator»
}

\author{
Antonio Lastra \\ Universitàt de Valencia
}

RESUMEN: El propósito de estas páginas es el de empezar a medir, si existe, la distancia, incluso el pathos de la distancia, que separaría Schopenhauer como educador, la tercera de las Consideraciones intempestivas, publicada en 1874 , de la frase «Nietzsche como educador» («Nietzsche als Erzieher») —un $\alpha \check{\pi} \alpha \xi \lambda \varepsilon \gamma o ́ \mu \varepsilon v o v$ absoluto en el cuerpo de su escritura—, con la que Friedrich Wilhelm Nietzsche (1844-1900) se habría apropiado en Ecce homo (la última voluntad de su psicología literaria, si podemos describir así este libro difícil de clasificar, escrito en 1888 y publicado póstumamente en 1908) de lo que había atribuido catorce años antes a Arthur Schopenhauer (fallecido en 1860): «Quien habla aquí no es en el fondo "Schopenhauer como educador", sino su antítesis, "Nietzsche como educador"».

Palabras clave: Nietzsche como educador - filósofo - cultura - Imperio (Reich)

ABSTRACT: The aim of this paper is to begin to measure, if it exists, the distance, even the pathos of distance, that would separate Schopenhauer as Educator, the third of the Untimely Considerations, published in 1874, from the phrase «Nietzsche as an educator» («Nietzsche als Erzieher») - an absolute $\alpha \check{\pi} \alpha \xi \xi \lambda \varepsilon \gamma$ ó $\mu \varepsilon v o v$ in the body of his writing-, with which Friedrich Wilhelm Nietzsche (1844-1900) would have been appropriated in Ecce homo (the last will of his literary psychology, if we can describe so this difficult book to classify, written in 1888 and published posthumously in 1908) of what he had attributed fourteen years earlier to Arthur Schopenhauer (died 1860): «Who speaks here is not basically "Schopenhauer as educator", but his antithesis, "Nietzsche as educator».

Keywords: Nietzsche as educator - philosopher - culture - Empire (Reich) 
"Es braucht viel Zeit, bis eine Welt untergeht — weiter aber auch nichts" sagt Gibbon.

Nachgelassene Fragmente Sommer-Herbst 1873 (NF1873, 29 [142]/FP I 499)

[...] denn wenn schon, wie Gibbon sagt, nichts als Zeit, aber viel Zeit dazu gehört, dass eine Welt untergeht, so gehört auch nichts als Zeit, aber noch viel mehr Zeit dazu, dass in Deutschland, dem "Lande der Allmählichkeit", ein falscher Begriff zu Grunde geht.

Vom Nutzen und Nachtheil der Historie für das Leben (1874) $\S 10($ OC I 743)

El propósito de estas páginas es el de empezar a medir, si existe, la distancia, incluso el pathos de la distancia, que separaría Schopenhauer como educador, la tercera de las Consideraciones intempestivas, publicada en 1874, de la frase «Nietzsche como educador» («Nietzsche als Erzieher») -un ö $\pi \alpha \xi \lambda \varepsilon \gamma o ́ \mu \varepsilon v o v$ absoluto en el cuerpo de su escritura-, con la que Friedrich Wilhelm Nietzsche (1844-1900) se habría apropiado en Ecce homo (la última voluntad de su psicología literaria, si podemos describir así este libro difícil de clasificar, escrito en 1888 y publicado póstumamente en 1908) de lo que había atribuido catorce años antes a Arthur Schopenhauer (fallecido en 1860): «Quien habla aquí no es en el fondo "Schopenhauer como educador", sino su antítesis, "Nietzsche como educador"》 (OC IV 824).

Nietzsche podría sugerir con estas palabras que no existe distancia alguna entre Schopenhauer como educador y «Nietzsche como educador», por lo que, no habiendo dejado en ningún momento de dar testimonio de sí mismo, la frase «Nietzsche como educador» respondería perfectamente a la pregunta (una pregunta «insoslayable [unerlässlich]») por quién es Nietzsche y cómo ha llegado a ser, en su condición de «educador»-como se puede leer en la primera de las caracterizaciones que ofrece de sí mismo en Ecce homo-, «un

1 He cotejado el original en alemán de Nietzsche en la Digitale Kritische Gesamtausgabe Werke und Briefe, basada en el texto crítico de Giorgio Colli y Mazzino Montinari, Berlín/Nueva York, Walter de Gruyter, 1967—, y editada por Paolo D'Iorio (http://www.nietzschesource.org/\#eKGWB), salvo el pasaje de la nota 6, y cito en español por la edición de los Fragmentos póstumos (FP, volumen y número de página) y las Obras completas (OC, volumen y número de página) al cuidado de Diego Sánchez Meca (Tecnos, Madrid, 2007-2016) y de la Correspondencia (CO, volumen y número de página) al cuidado de Luis Enrique de Santiago Guervós (Trotta, Madrid, 2005-2012). Véase la nota 5 para la tercera y última mención de Edward Gibbon en el corpus nietzscheano (NF-1881, 11 [249]/ FP II 812-813). 
discípulo del filósofo Dioniso [ein Jünger des Philosophen Dionysos]» o en la última- un «destino» e incluso el propio Dioniso, «Dioniso contra el crucificado...». Pero una cosa es Nietzsche y otra sus escritos. El «problema educativo sin parangón [Problem der Erziehung ohne Gleichen]» que, con los nombres (o pseudónimos) de Schopenhauer y Wagner, «Nietzsche como educador» habría planteado en las dos últimas Intempestivas y, al parecer, resuelto en el otoño de 1888 en nombre propio o en el de Dioniso, nos obliga a ser extremadamente cuidadosos al comparar el escrito, y las enseñanzas, de Schopenhauer como educador con las enseñanzas del «ego ipsissimus», el Selbst inscrito en «Nietzsche como educador» (cf. FP IV 178 y OC III 775 con IV 781-782, IV 809, IV 823, IV 859 y el poema 〈Última voluntad〉 de los Ditirambos de Dioniso, IV 883-884).

Nietzsche le había atribuido a Schopenhauer, por encima de todo, la condición de «filósofo», que entonces y ahora habría de recaer sobre el propio Nietzsche, y, con su Intempestiva, no habría tratado sino de remover los obstáculos que impedían que la filosofía surtiera efecto en sus contemporáneos, que los «educara» contra su época; la plena eficacia del filósofo consistiría, de hecho, en que «educara de nuevo a filósofos [der Philosoph wieder Philosophen erziehe]» (OC I 792). «De nuevo» aludiría tácitamente a una escena previa de instrucción en la que un filósofo, no el «Estado» ni institución educativa alguna, habría educado a otros filósofos, que no adquirirían espontáneamente su condición de filósofos sino solo en virtud de la educación recibida de otro filósofo. Al igual que Sócrates en la República de Platón, Nietzsche guarda silencio respecto a quién habría educado al primer filósofo: la escena previa de instrucción no es, seguramente, la escena original. El dios Dioniso, al fin y al cabo, es un filósofo y, como dirá Nietzsche en Más allá del bien y del mal, los dioses también filosofan (OC IV 433-434). A diferencia de esa escena original desconocida, la escena previa de instrucción es relativamente fácil de situar en la historia de la filosofía y recibe de manera apropiada su nombre de un filósofo mucho más reticente que Nietzsche (o que Schopenhauer) a la hora de inscribirse a sí mismo en su escritura: compárese el inicio del Fedón (57 a:

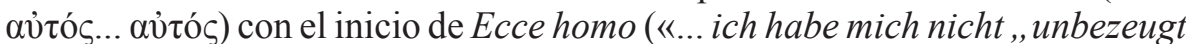
gelassen “») o el inicio de El mundo como voluntad y representación («,Die Welt ist meine Vorstellung“"»). Cualquiera que sea el interés del Estado y de las instituciones educativas contemporáneas por la filosofía, habría de supeditarse a la «idea platónica», una idea que Nietzsche enfatiza que «educa» (OC I 775). Schopenhauer como educador era, por tanto, una consideración «intempestiva» porque rememoraba una escena previa y una tradición -la tradición de la filosofía política platónica que habría seguido a esa escena previa de instrucción y que incluiría, además de los diálogos, la fundación de la Academia- que habrían dejado de surtir efecto, de ser plenamente eficaces, 
cuando Nietzsche la escribe: los contemporáneos de Schopenhauer y del propio Nietzsche preferían «educar a ciudadanos [Staatsbürger zu erziehen]» antes que a filósofos, mientras que Schopenhauer y Nietzsche, como Sócrates, estimaban más su filosofía que a sus contemporáneos (OC I 760 y I 804; cf. Apología de Sócrates 29 d).

Nietzsche advierte, además, que la «fundación del nuevo Imperio alemán [die Gründung des neuen deutschen Reiches]» en 1871 no habría sido un acontecimiento estrictamente político, sino que habría afectado también a la comprensión contemporánea de la relación de la filosofía con el Estado -a la comprensión misma de la filosofía política-, de manera que esa relación ya no podría considerarse en absoluto platónica: «Ahora se tiene el poder; entonces, en la época de Hegel, se lo quería tener -en esto hay una gran diferencia [Man hat jetzt die Macht: damals, zur Zeit Hegels, wollte man sie haben - das ist ein grosser Unterschied]» (cf. OC I 767 con I 804). «La época de Hegel» remite a la Revolución francesa, las guerras de liberación y el establecimiento de la Universidad de Berlín, cuyo currículum favorecía la interpretatio graeca de la historia universal en detrimento de la bíblica, incluso entre los teólogos, y educaría, como ciudadanos, a los contemporáneos de Schopenhauer, provocando así la reacción del filósofo; pero, como «educador», Schopenhauer -como acabará reconociendo Nietzsche en un fragmento póstumo del otoño de 1887- no habría sido más que un «rebrote» (Nachschlag) de la situación anterior a la Revolución, "au fond buen siglo XVIII», y -como dirá en Crepúsculo de los ídolos - un «heredero de la interpretación cristiana [der Erbe der christlichen Interpretation]» (FP IV 288 y OC IV 665). No está claro que, a diferencia de Hegel, el filósofo como educador, el filósofo que ha de educar a otros filósofos, quiera tener el poder -ni servir al Estado en la educación de los ciudadanos- o sea el portador de un saber absoluto y una voluntad de poder. Schopenhauer como educador no es «Nietzsche como educador» si la voluntad de poder ha de formar parte de sus enseñanzas. Quién tendría el poder «ahora», es decir, en 1874, o quién lo tiene siempre, no es en modo alguno una pregunta retórica. En cualquier caso, la fundación de un imperio no es el equivalente de la fundación de una ciudad del logos (República 369 b). ${ }^{2}$

2 Véase Karl Löwith, Von Hegel zu Nietzsche. Der revolutionäre Bruch im Denken des neunzehnten Jahrhunderts [1950], S. Fischer, Stuttgart, 1960, pp. 330-33. La frase «voluntad de poder [Wille zur Macht]» aparece por primera vez en un fragmento póstumo de finales del verano de 1876 (FP II 340). Véase el importante Ensayo de autocrítica〉 que precede a la segunda edición (1886) de $E l$ nacimiento de la tragedia (OC I 329-336). Como Sócrates en la Apología, Nietzsche relaciona su tarea con haber servido en la guerra, pero las batallas que Sócrates enumera fueron derrotas de los atenienses, mientras que las batallas que Nietzsche menciona fueron victorias de los prusianos. Traduzco Reich por «Imperio» contra la costumbre generalizada de mantener la palabra en alemán (véase el Deutsches Wörterbuch von Jacob Grimm und Wilhelm Grimm, digitalisierte Fassung im Wörterbuchnetz des Trier 
En el sentido de la antigua retórica al que san Agustín aún podía recurrir, podríamos suponer que la frase «Nietzsche como educador» funciona gramaticalmente mejor como una retractatio que como una «antitesis [Gegensatz]», aunque no es probable que Nietzsche estuviera más cerca como filólogo de lo que estaba, «como fisiólogo y médico radical», de la proposición de san Agustín cuando rememorara lo que había escrito en sus Confesiones (Hoc in me egerunt cum scriberentur, et agunt cum leguntur) que, por ejemplo, de los prefacios que Henry James escribió para la edición neoyorquina de sus obras entre 1905 y 1907: ser intempestivo, desde luego, no tiene que ver solo con los contemporáneos; la mirada al pasado puede necesitar su propia intempestividad. El protagonista de la novela inacabada de James The Sense of the Past (El sentido del pasado) -el joven Ralph Pendrel, autor de un ensayo sobre cómo ha de leerse la historia que no es incomparable en modo alguno con la segunda de las Intempestivas - descubre su propio carácter intempestivo al sondear el tiempo que hace falta para que un mundo se desmorone; al volver al pasado, se encuentra con otro «Ralph Pendrel» que ha leído con atención su ensayo y puede anticiparse al futuro del joven. Por su parte, san Agustín narraría la misma experiencia con el tiempo, pasando del género autobiográfico al histórico, en La ciudad de Dios. ${ }^{3}$ El desmoronamiento del mundo de Nietzsche, su repentino Zusammenbruch poco después de escribir Ecce homo, es, en cualquier caso, una advertencia respecto al tiempo, y la distancia, que hacen falta para que «un concepto falso [ein falscher Begriff]», en la «paulatina» Alemania, en Londres o en Hipona o en cualquier otra parte,

Center for Digital Humanities, Versión 01/21, https://www.woerterbuchnetz.de/DWB, consultado el 25 de agosto de 2021, s.v. Reich.) Véase, sin embargo, una excepción significativa en el pasaje de Ecce homo en OC, que hay leer bien, en el que Nietzsche vincula (y es la única ocasión en que lo hace) la «voluntad de poder» al «Imperio»: «la voluntad de poder (de "Imperio") [den Willen zur Macht (zum „,Reich“)]» (OC IV 848; en el mismo párrafo, el traductor deja sin traducir la segunda mención de Reich: «mero alemán del Reich [blossen Reichsdeutschen]» [IV 849]). En diciembre de 1888, en el borrador de una carta a Ruggero Bonghi, Nietzsche escribió que «el príncipe Bismarck no ha pensado nunca en el Imperio [Fürst Bismarck hat nie ans ,,Reich “ gedacht]» (CO VI 368), y volvería a emplear el término Reich en la carta del 3 de enero de 1889 a Meta von Salis (CO VI 371: «Acabo de tomar posesión de mi imperio») y en la carta de 6 de enero del mismo año a Jacob Burckhardt (CO VI 377: «reino de Dios [,,Reich Gottes“]»).

3 Véanse Retractationes 2.6 y Henry James's New York Edition. The Construction of Authorship, ed. de D. McWhirter, Stanford: Stanford University Press, 1995. The Sense of the Past se publicó póstumamente en 1917. Sobre «la curiosidad de un médico y fisiólogo radical» con la que Nietzsche leyó las Confesiones de san Agustín («¡Oh ese viejo rétor! [...] Algo así es asquerosamente mentiroso»), véase la carta a Franz Overbeck de 31 de marzo de 1885 (CO V 56), en la que describe el platonismo, que san Agustín «plebeyiza», como «un modo de pensar que fue pensado para la suprema aristocracia del alma». No he logrado encontrar en el corpus nietzscheano ninguna alusión a La ciudad de Dios. Sobre la omisión de la filosofía medieval en la obra de Nietzsche y su sustitución por el concepto general de «teología» volveré luego (véase el importante fragmento póstumo del verano de 1873, 29 [46], en FP I 470). 
se desmorone igual que se desmoronan un mundo o un ser humano: en última instancia, que «Schopenhauer [o Sócrates o Platón o Hegel] como educador», o «Nietzsche como educador», sean o no conceptos falsos depende de lo que el mismo Nietzsche entendiera, al principio y al final de su vida como filósofo, por «filósofo como educador»y, en general, por «filósofo», por la vida de la filosofía, y dilucidar lo que sea vivir como un filósofo -en la misma medida que dilucidar lo que sean la vida de un santo (en el caso de Agustín, por ejemplo) y la vida de un artista (en el caso de James, que en Nietzsche fue siempre «el caso Wagner»), en una trinidad perfectamente coherente y, por otra parte, profundamente emersoniana en el contexto de Schopenhauer como educador (véase el §5) - es algo que requiere demasiado tiempo y ninguna época puede acotar del todo. Que la vida de la filosofía no pueda entenderse disociada de la educación o de la ausencia de educación -que la filosofía sea la educación par excellence - era, naturalmente, lo que los filósofos antiguos y, especialmente, Sócrates y Platón, pensaban. ${ }^{4}$

Saber lo que pensaban Sócrates y Platón y, en general, estar en condiciones de interpretar correctamente o encontrar una vía de acceso a lo que los antiguos habían dicho, al sentido del pasado o histórico, no es, sin embargo, la tarea propia de un filósofo, a quien -como podemos leer en Schopenhauer como educador - no le concierne, en rigor, la historia de la filosofía, al margen de que Nietzsche acabara suscitando con «el problema de Sócrates» la sospecha de que, a diferencia de los sofistas, Sócrates no fuera griego en absoluto, de que la filosofía misma no tuviera nada que ver con la sabiduría trágica de los antiguos o solo tuviera que ver con la ciudad antigua como «antítesis»: la antítesis, en este caso, de la decadencia de la polis. (En la primera anotación de Nietzsche sobre Sócrates, en el otoño de 1869, a la sospecha de que Sócrates fuera colaborador de Eurípides le seguía la proposición de que Sócrates «pertenec[iera] a los sofistas» [FP I 63].) Con un término tomado más de la gramática que de la historia y reiterado con frecuencia desde El nacimiento de la

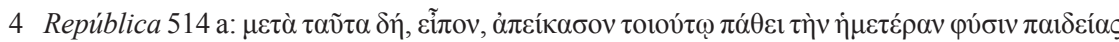

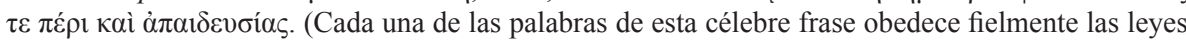
de la necesidad logográfica que luego mencionaré.) Véase el uso del término Zusammenbruch («el último misterio de Nietzsche», pero también el colapso del Segundo Imperio alemán) en W. H. F. Altman, Friedrich Nietzsche. The Philosopher of the Second Reich, Lanham: Lexington Books, 2013, p. 188 et passim, que ha sido una fuente inagotable de consulta para la redacción de estas páginas. Aunque Altman se pregunta si Nietzsche era «en absoluto un filósofo» (§ 105) o si era «alemán» (§ 24), no lo considera nunca un «sofista» (un término que no aparece en el libro al margen del título del diálogo platónico); sin embargo, la mejor definición de «sofista» es lo que Altman llama el «viejo problema de Nietzsche»: querer el ethos del platonismo sin la metafísica de Platón ( $\$ 139$; cf. «El problema de Sócrates〉 en Crepúsculo de los ídolos [OC IV 625-630]). Repárese, con todo, en que ni ethos (en el sentido habitual de «ética» o «moral») ni «metafísica» son términos platónicos. Véase también Christian Niemeyer, Nietzsche als Erzieher. Pädagogische Lektüren und Relektüren, Weinheim/Basilea: Beltz, 2016. 
tragedia -donde aparece la expresión «cultura [Cultur] socrático-alejandrina» (OC I 420) -, Nietzsche hablará de «alejandrinismo [Alexandrinismus]» para referirse tanto a lo que habría que interpretar en un texto antiguo como a quien habría de interpretarlo, a la «traducción [o transmisión o transferencia a la actualidad] de una cultura extraña [die Übertragung einer fremden Cultur]» (FP II 179-180). En un fragmento póstumo de la primavera-verano de 1875 se lee: "“Ilustración" y cultura [Bildung] alejandrina es -jen el mejor de los casos!- lo que quieren los filólogos» (FP II 89), y añade: «No helenidad». No resulta fácil de dilucidar a quién habría de resultarle la «helenidad» una «cultura extraña» si Epicuro o Lucrecio o Spinoza (en una serie no del todo arbitraria) no combatían, con su filosofía, el paganismo o la romanitas o la propia modernidad; en una frase que hay que leer bien, Nietzsche escribe que «en el Imperio romano todo espíritu respetable era epicúreo [jeder achtbare Geist im römischen Reich war Epicureer]» (OC IV 764; cf. OC III 527-528 y FP IV 193).

«Filólogo» alude, naturalmente, a la profesión de Nietzsche en la Universidad de Basilea desde 1869 hasta 1879 -cuando los «espíritus libres» empezaron a sustituir a los estudiantes (de filología) como discípulos (o lectores) de Nietzsche, antes de que empezara con Zaratustra a dirigirse «a todos y a nadie» y de que leer a Nietzsche empezara a ser el problema que sigue siendo para nosotros-, pero, en la revisión de Schopenhauer como educador que Nietzsche llevaría a cabo en Ecce homo, justo después de la revelación de «Nietzsche como educador» como verdadero autor de la Intempestiva, Nietzsche dirá que su «oficio [Handwerk]», un oficio que conocía bien, era entonces, cuando la escribió, el de Gelehrte, a diferencia de su «tarea [Aufgabe]» (en cursiva en el original) - una tarea cuya dificultad había especificado en el segundo epígrafe de la Intempestiva como la de «educar a un ser humano para que se convierta en un ser humano»-, y agregaba que el «fragmento de psicología» del Gelehrte que Schopenhauer como educador ofrecía expresaba un «sentimiento de distancia [Distanz-Gefühl]» (en cursiva en el original) respecto a sí mismo, como educador, y a su mundo de discípulos o lectores. Establecer las diferencias que haya entre educar a un ser humano para que se convierta en un ser humano, educar a los ciudadanos del Estado (o del Imperio) y educar a filósofos exige desde luego guardar las distancias; en cualquier caso, la distancia entre el filósofo en el que Nietzsche se había reconocido en Schopenhauer, el Gelehrte que él mismo era cuando escribe su Intempestiva y el ecce homo que llegaría a ser. En qué medida un Gelehrte -que en apariencia ocuparía una posición intermedia entre el filósofo y el ser humano, tal vez la posición intermedia de la civilización entre la humanidad y la filosofía- podría ser también un educador, de quién recibiría entonces su educación y a quién estaría en condiciones de educar son preguntas que 
naturalmente nos salen al paso.

Los traductores de Nietzsche al español no siempre se han mostrado conformes respecto a la traducción adecuada de Gelehrte por «docto»o «erudito» e incluso «sabio» e «intelectual», en el mismo campo semántico que «filólogo», «anticuario», «lingüista», «historiador» (OC I 800) o «alejandrino», y que Nietzsche vinculara su sentido, o su ausencia de sentido, a la Ilustración -al «buen siglo XVIII» en el campo semántico aun más extenso de la historia de la educación en general- no hace más que reproducir, a finales del siglo XIX y en medio de la polémica creada por El nacimiento de la tragedia y la «filología del futuro», la Querelle des Anciens et des Modernes que precisamente la Ilustración habría querido zanjar para señalar el final irreversible de una época y la plena legitimidad de la modernidad. ${ }^{5}$ Cualquiera que sea la forma como la Querelle se haya manifestado en la historia -desde que Platón estableciera la antigua diferencia entre la filosofía y la poesía que Nietzsche ya consideraba una señal de alejandrinismo o decadencia-, ha afectado siempre a la educación: Platón critica a Homero como educador en el mismo sentido en el que Nietzsche defenderá, en la tercera Intempestiva, al filósofo como educador; el filósofo, dirá Nietzsche en Schopenhauer como educador con un lenguaje plenamente figurativo, adquiere «poder para, mediante él, ayudar a la physis [Macht zu gewinnen, um durch sie der Physis nachzuhelfen]»; ayudar a la naturaleza, «transfigurar [verklären]» la naturaleza, daría como resultado la «cultura» y «cultura», en el vocabulario de Schopenhauer como educador y de buena parte de la obra de Nietzsche, es el término para la meta (la «espiritualidad [Geistigkeit]», mencionada por última vez en Ecce homo) de todos los impulsos e instituciones educativas a los que Nietzsche concedía que tuvieran un futuro o un destino. Al igual que ocurre con Gelehrte, la ecdótica nietzscheana, que incluye también la traducción y el comentario, ha de distinguir cuidadosamente el uso que Nietzsche hace de los términos Kultur, Cultur, Formung, Bildung o Erziehung -este último cargado, por otra parte, de connotaciones lessinguianas-, que no es en modo alguno intercambiable en todas las ocasiones. (En una anotación

5 Véase la obra del joven Gibbon Ensayo sobre el estudio de la literatura (ed. de A. Lastra, Ediciones del subsuelo, Barcelona, en curso de publicación), en la que el futuro historiador de la Declinación y caída del Imperio romano mantiene la tensión entre el neologismo érudit, asociado en la primera mitad del siglo XVIII al trabajo de las órdenes religiosas y las Académies reales, y la traducción contemporánea (semántica y práctica) de los philosophes, que lograrían ocupar su lugar: la Encyclopédie es, con esta perspectiva, una inmensa obra de sustitución epistemológica. Gibbon escribió su ensayo en francés, lengua en la que Nietzsche pensó a veces que habría sido más apropiado escribir su obra. Gibbon la había aprendido en Lausana y a la «helvetización [Verschweizerung]» como estímulo para los «sentimientos supranacionales» alude Nietzsche en su última mención del historiador en 1881 (junto a Voltaire, el mentor de los libros «ilustrados» de Nietzsche), tras su marcha definitiva de Basilea (FP II 812-813). 
muy temprana del invierno de 1869, Lessing, a quien no podemos negar su condición de «educador», figura «como el erudito ideal [als der ideale Gelehrte]» [FP I 87]. Su Educación del género humano podría prefigurar la enseñanza del eterno retorno en la misma medida, pasando del fondo a la forma, en que Nietzsche reconocería en la prosa de Lessing una pauta de la suya.) En su Introducción al estudio de los Diálogos de Platón, el curso que impartiría en Basilea entre 1871 y 1876 (desde un año antes de la publicación de El nacimiento de la tragedia hasta dos años después de la publicación de Schopenhauer como educador, cuando apareció la cuarta y última de las Intempestivas), Nietzsche advirtió que el problema de la escritura platónica -que para nosotros se convierte en el problema de la lectura de la filosofía en general- suponía «una discusión de principios, a partir de la cual pudo haber surgido la decisión de fundar la Academia», es decir, la primera institución educativa y el modelo de todas las que han aparecido después (OC II 509). Es impensable que, mucho más que la $\pi \alpha \rho \rho \eta \sigma i ́ \alpha$, no valga para la escritura nietzscheana, para su exigencia de escribir bien y de leer bien, la necesidad logográfica platónica. ${ }^{6}$ Tal vez «educación», «formación» o «cultura» puedan decirse de muchas maneras y la ambigüedad filosófica, humana y civilizada del Gelehrte sea difícil de eliminar e incluso insuperable en la práctica, pero «Nietzsche como educador» es una frase única y su aparente precisión pone a prueba al intérprete.

En cualquier caso, cultura es una extraña palabra latina, un precipitado de la traducción como lengua franca y de la transmisión o transferencia de las enseñanzas entre lenguas, generaciones e incluso épocas y climas distintos, a la que volveremos en seguida. En la distancia que separa la tercera Intempestiva de la revisión final de su escritura en Ecce homo -apenas el tiempo de una generación-, Nietzsche se dejó por el camino a una figura difícil de clasificar en el terreno de la filosofía como educación y de la propia «cultura»: la del «americano» (como se refiere a él en Schopenhauer como educador) Ralph Waldo Emerson. «No sé qué daría -le escribirá diez años despúes a Overbeck, en diciembre de 1884, tras la publicación de las tres primeras partes de Así habló Zaratustra - por conseguir de algún modo, aunque tardíamente, que una personalidad tan magnífica, grande, rica en alma y espíritu se sometiese a una severa disciplina, a una auténtica formación científica [wirkliche

6 Compárese Fedro 264 b con la frase más platónica de Nietzche: «No hemos de pensar en una difusión considerable del escrito en tiempos de Platón, sino solo en una comunicación a los amigos. El contenido de la República sobrepasa todo cuanto podría permitir la parresía [ $\pi \alpha \rho \rho \eta \sigma i ́ \alpha$ ] en el Estado más libre [Wir haben uns ein wesentliches Bekanntwerden der Schrift zu Platos Lebzeiten nicht zu denken, sondern nur ein Mittheilen an Freunde. Der Inhalt der Politeia übersteigt alles, was die Parr $<h>$ esia im freiesten Staat erlauben könnte]» (OC II 477; Nietzsche Werke, Kritische Gesamtausgabe, ed. de G. Colli y M. Montinari, Berlin: Walter De Gruyter, 1995, II 4, p. 57). 
wissenschaftliche Cultur]. ¡Tal como están las cosas, en Emerson hemos PERDIDO a un filósofo!» (CO IV 514). Entre la primera mención de Emerson en el corpus (la carta a Carl von Gersdorff de 17 de abril de 1866, CO I 381), en la que menciona la descripción emersoniana de los «días del cielo» en verano que le hacen sentir la «entera perfección de la naturaleza [wird die Natur vollkommen]», y el retorno de su «alegre serenidad benévola [gütige und geistreiche Heiterkeit]» en Crepúsculo de los ídolos, publicado en 1889 (OC IV 662), que Emerson se hubiera perdido como «filósofo» por falta de una «auténtica cultura científica» plantea algunos interrogantes a los lectores de Emerson y de Nietzsche y nos obliga también a ser algo más precisos, a ser semánticamente más justos con el American Scholar, la denominación con la que -por encima de la de «poeta» o «filósofo»- Emerson se presentaría a sí mismo, tras abandonar la profesión eclesiástica, en 1836. Walter Kaufmann, en cuya influyente interpretación de Nietzsche, dirigida de manera preferente al lector americano (o contemporáneo), no cuenta demasiado la escena de instrucción emersoniana, tradujo, no sin alguna vacilación, Gelehrte por Scholar en su edición de Más allá del bien y del mal, donde Nietzsche describió del modo más completo el programa de los «escolares» (o eruditos). (Véase allí la referencia a Schopenhauer, OC IV 369) ${ }^{7}$

En cualquier caso, ser justos con Emerson, con una perspectiva nietzscheana, supondría, sobre todo, admitir la posibilidad de que, además de Schopenhauer o Wagner, Emerson, el «profesor de la Ciencia Jovial» (como se llamaría a sí mismo en sus Diarios), hubiera podido ser también un educador de Nietzsche o de que Nietzsche - por hablar a su manera- hubiera podido servirse de Emerson como de una semiótica. Emerson fue, de hecho, el educador de Henry David Thoreau, cuya obra maestra, Walden, publicada en 1854 -cuando Thoreau tenía la misma edad con la que Nietzsche publicaría

7 Sobre la relación de Nietzsche con Emerson, véase mi «Prometeo vencido: Emerson y Nietzsche>, en La filosofía y los dioses de la ciudad, Valencia: Aduana Vieja, 2011, pp. 96-104. Véase también la traducción de 〈The American Scholar〉 de Emerson (con la justificación de verterlo por 〈El escolar americano〉) en Naturaleza y otros escritos de juventud, ed. de J. Alcoriza y A. Lastra, Madrid: Biblioteca Nueva, 2008, pp. 91-112. Sobre Kaufmann, véase la Introducción a su traducción de Die fröhliche Wissenschaft (The Gay Science, Nueva York: Vintage Books, 1974, pp. 7-13) y Stanley Corngold, Walter Kaufmann. Philosopher, Humanist, Heretic, Princeton: Princeton University Press, 2019. Tanto en Scholar como en «escolar» se mantiene la raíz griega de $\sigma \chi 0 \lambda \eta ́$, el otium o tiempo libre que el filólogo ha de tomarse y que Nietzsche reclamaba para la filosofía del futuro. Schuler no aparece, que yo sepa, en el vocabulario de Nietzsche, pero véase el interesante fragmento póstumo de finales de 1876, donde figura el término Schulereigniß («suceso escolar», FP II 346; cf. también el mencionado $\S 295$ de Más allá del bien y del mal: los dioses pueden ir a la escuela [Schule] con los hombres [OC IV 434], y «la primera propedéutica de la espiritualidad [die erste Vorschulung zur Geistigkeit]» del importante $\S 6$ de 〈Lo que les falta a los alemanes〉 en Crepúsculo de los ídolos). Lo que dice Nietzsche, por otra parte, en ese mismo fragmento sobre «la buena obra de arte narrativa», y explica en parte su manera de escribir, podría encontrarse en cualquiera de los Prefaces y narraciones de James. 
Aurora, dos libros sutilmente afines, contemporáneos entre sí e intempestivos en su época-, es una prueba de que la educación (paulatina, enigmática y oracular si se quiere, como respuesta a una serie de preguntas que el educador plantea, pero que no responde nunca, y para la cual el discípulo no dispone nunca de demasiado tiempo) puede ser plenamente eficaz. Esa eficacia no resulta difícil de aceptar en la actualidad y tal vez podamos pensar en que el éxito tuviera que ver con una educación al margen del Estado y las instituciones educativas, desarrollada al hilo de conversaciones y lecturas recíprocas, de sociedad y soledad, no exenta de malentendidos y de reconocimientos aplazados y capaz de forjar una identidad inconfundible, en muchos aspectos una «distinción» o Vornehmheit como la que Nietzsche buscó hasta el final de su vida: la aparición de un individuo radical que no habría dejado, sin embargo, de pertenecer a la comunidad, la «revolución atómica» (OC I 770) con su reafirmación social, positiva y participativa. Con esta perspectiva, Walden donde la palabra «estudiante» desempeña un papel relevante (cf. OC I 536)-, 〈Desobediencia civil〉 o 〈Vida sin principio〉 de Thoreau serían, en efecto, ejemplos radicales de la escritura constitucional de un individuo y de una comunidad justo donde «constitución» y «carácter» (términos frecuentes en la escritura trascendentalista de Emerson y Thoreau) se entrecruzan y permiten lo que Thoreau consideraba una comunicación central con sus lectores. Si tratáramos de reconstruir, para una escritura constitucional comparada, el significado de «constitución» (Verfassung) y su campo semántico en la escritura de Nietzsche las dificultades serían, por el contrario, casi insuperables: ni Schopenhauer como educador (véase el $\S 5$, OC I 779) ni «Nietzsche como educador» podrían salir en nuestra ayuda. Solo Emerson, en cualquier caso, entre los trascendentalistas, sobrevivió a una Guerra de Secesión que acabó fortaleciendo la «Unión», y es probable que el pragmatismo, al que ayudó a educar y que nunca ha ocultado su simpatía por Nietzsche, contribuyera a la transformación republicana de la «gran política» en un imperio en la misma medida en que es casi imposible disociarlo de las grandes instituciones educativas. Si, como advirtió Stanley Cavell, es preciso aguzar el oído para captar la transfiguración de las frases emersonianas en la escritura de Nietzsche, no es menos preciso hacerlo para captar la transfiguración de las frases nietzscheanas entre las consecuencias del pragmatismo. El crecimiento de la cultura, dice una de esas frases emersonianas, puede hacer que un hombre se vuelva invisible para sus contemporáneos. ${ }^{8}$

Podríamos preguntarnos si querer el «carácter» emersoniano (para

8 Véase mi reseña del libro American Nietzsche de Jennifer Ratner-Rosenhagen en Aprender leyendo, Madrid: Ápeiron, 2018, pp. 191-194, y mi «Stanley Cavell y la cultura contemporánea〉, en Emerson como educador, Madrid: Verbum, 2007, pp. 145-163. 
el que Nietzsche habría reservado un término casi exclusivo de su propia idiosincrasia: Heiterkeit, «serenidad» o «jovialidad», que había atribuido con menos énfasis a Schopenhauer: cf. OC I 767 con OC IV 617 y IV 661-662) sin la «constitución» emersoniana no equivale a la dificultad, o imposibilidad, de querer el ethos platónico sin la metafísica platónica o a la exigencia de que «cultura», en cualquiera de sus acepciones, adquiera el sentido de un «desaprendizaje» radical y una «transvaloración de todos los valores»: Umlernen aparece, de hecho, por primera vez en la escritura de Nietzsche en Schopenhauer como educador (OC I 787) y encuentra su límite conceptual en Más allá del bien y del mal, donde el «filósofo» deja paso al «pensador» y Umlernen a Auslernen (OC IV 392). «Aprender hasta el final» o «completar el aprendizaje» es, sin duda, la clave de bóveda de toda la educación. Si el American Scholar se había perdido como «filósofo», si el Gelehrte resulta extraño a la cultura, ¿qué clase de filósofo, de ser humano y de ciudadano podría hacerse cargo entonces de la educación? ${ }^{9}$

En un fragmento póstumo de principios de 1874, recién publicadas las dos primeras Intempestivas, Nietzsche escribió que «había que seguir luchando con los griegos como Cicerón [Es ist nach der Art Cicero's fortzuringen mit den Griechen]» (FP I 535) y es posible, por lo que le escribe a Carl von Gersdorff en febrero de ese mismo año, que «Cicerón y el concepto romano de cultura [Cicero und der romanische Begriff der Cultur]» hubiera podido llegar a convertirse en la tercera Intempestiva en lugar de Schopenhauer como educador (CO II 446). La admiración de Nietzsche por Cicerón, de la que hay testimonios de una delicadeza (o «salvación») casi lessinguiana en los fragmentos póstumos, se resume, en última instancia, en un deseo expresado en el verano-otoño de 1884: que el auténtico concepto de filosofía no se desmorone en Alemania («Was ich wünsche, ist, daß der ächte Begriff des Philosophen in Deutschland nicht ganz und gar zu Grunde gehe», FP III 746). El concepto ciceroniano, más que romano, de «cultura», para el que Cicerón tuvo que acuñar incluso la palabra, era una traducción y una transferencia del concepto platónico, más que griego, de «filosofía». Todo el pasaje de las Tusculanas donde aparece se escribe sobre el intento fallido de Calicles de refutar a Sócrates en Gorgias y es, por decirlo así, la anticipación de la expresión de un deseo nietzscheano ante litteram: que el auténtico concepto de filosofía, extraño a la "cultura» romana, no se desmoronase en Roma. Cicerón, sin embargo, está más cerca de quienes, dotados de una «educación liberal [liberaliter eruditi]», pueden convertirse en filósofos que de aquellos

9 Sobre el trasfondo de Schopenhauer como educador y la relación entre Schopenhauer (y Emerson) como educador y el proyecto de una Intempestiva dedicada a «Nosotros los filólogos», véase Laurence Lampert, What a Philosopher Is. Becoming Nietzsche, Chicago: The University of Chicago Press, 2017, especialmente los capítulos 2 y 3. 
«que quieren llamarse filósofos [qui se philosophos appellari volunt]» y nada cuesta reconocer como sofistas. A Nietzsche (al menos, al Nietzsche que habría podido escribir «Cicerón como educador») no le habría costado seguir la reescritura platónica de Cicerón (post meridiem in Academiam descendimus [...] nam efficit hoc philosophia [...] complexa naturam [...]) hasta dar con la frase en la que la filosofía ha de traducirse inequívocamente como «cultura del alma»: cultura autem animi philosophia est. Lo decisivo, lo que constituye el pathos y el sentimiento de la distancia entre Schopenhauer como educador $\mathrm{y}$ «Nietzsche como educador», es saber en qué momento Nietzsche pudo perder el rastro de esa escritura que vinculaba la filosofía como cultura con la educación de otros filósofos y la profunda moderación de la ciudad antigua. ${ }^{10}$ Franz Overbeck en la teología, Jacob Burckhardt en la historiografía y Erwin Rohde en la filología muestran el non sequitur de las enseñanzas de Nietzsche en la comunicación entre amigos y su proyección inevitable en el horizonte del Imperio alemán.

Franz Overbeck, que por razones de amistad y de fidelidad, unidas a su propia condición de teólogo desencantado, pudo aspirar más que ningún otro de sus contemporáneos a ser el discípulo aventajado de Nietzsche, se preguntó, mudo de perplejidad, en qué medida podían serlo Elizabeth Forster, la hermana de Nietzsche, o «Peter Gast», y hasta qué punto el NietzscheArchiv, para merecer su nombre en el futuro, podía ser el equivalente de la Academia platónica ( ¡o de la Iglesia!) para la enseñanza de las grandes doctrinas de su amigo, más o menos «secretas» o «fantásticas»: el eterno retorno, la inocencia del devenir, la muerte de Dios, el superhombre... Que el propio Overbeck, que durante un tiempo inconmensurable para nosotros fue el lector absoluto de El Anticristo, se sirviera de esas enseñanzas como de una semiótica para establecer la constitución histórica del cristianismo primitivo y el valor de los ideales ascéticos no podría revertir, en su propia tarea docente y en sus escritos, en la educación de los ciudadanos del Imperio alemán, lo que condicionaría su prolongada carrera, más o menos marginal, como profesor de Teología en Basilea muchos años después de la salida de su amigo de la universidad. La famosa frase dirigida al historiador Heinrich von Treitschke cuando la Kulturkampf dejara paso, con una fanática coherencia, al antisemitismo en Alemania -y sobre la que Jacob Taubes edificaría su influyente interpretación de Overbeck-, «regresar al cristianismo en aras de este Imperio [um dieses Reichs willen zum Christentum zurückzukehren]», no afectaba solo, sin embargo, a toda una generación teológico-política de

10 Leo el platónico $\pi \alpha ́ \theta \varepsilon ı$ del pasaje citado de la República (supra nota 4) para medir la distancia, el pathos de la distancia, entre filosofía y educación. Cicerón no se olvida, en su construcción

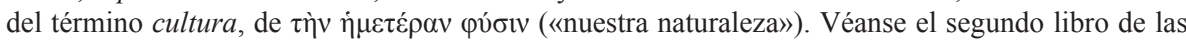
Tusculanas y Gorgias 482 c-486 d. 
protestantes más o menos capaces de leer a Nietzsche, cualesquiera que fueran las reacciones a sus enseñanzas, sino a la estimación retrospectiva del propio Nietzsche, en quien la «cultura» habría obliterado todos los caminos hacia la religión, pero no hacia el Estado ni el Imperio: El Anticristo suponía a los ojos de Overbeck un desequilibrio fatal entre el Reich Gottes y el Imperium romanum. ${ }^{11}$ Jacob Burckhardt, en cuya distinción había confiado Nietzsche hasta el final -hasta la citada carta de enero de 1889-, verá lo mismo cuando, en sus póstumas Consideraciones sobre la historia universal, tratara en vano, retrotrayéndose al pesimismo de Schopenhauer -que seguía siendo para él el auténtico filósofo- y pasando por alto a «Nietzsche como educador», de hacer de la «cultura» una potencia intermedia entre la religión y el Estado, evocando la «pregunta eclesiástica [die kirchliche Frage]» y la pertinencia en la actualidad (Burckhardt murió en 1897) de la «transformación general del modo de pensar a la manera de los siglos III y IV [allgemeine Veränderung der Denkweise wie etwa im III. und IV. Jahrhundert]». ${ }^{12}$

La «pregunta eclesiástica» y la «transformación general del modo de pensar a la manera de los siglos III y IV» son, en manos de Burckhardt, una evocación mucho más precisa desde el punto de vista historiográfico que cultural y señalan en la dirección del límite que la obra de Gibbon había marcado a los historiadores posteriores: la höhere Philologie, sin excluir siquiera la obra de Theodor Mommsen, no se había librado del temor a no poder dar un paso más allá de donde había llegado Gibbon en su Historia de la declinación y caída del Imperio romano. El límite que Gibbon había señalado para el desmoronamiento de un mundo y de los conceptos falsos que lo acompañaban se había ido desplazando a lo largo de los mil quinientos años de Antigüedad Tardía y Edad Media a los que Nietzsche raramente aludiría en su obra salvo como Imperium romanum. En Schopenhauer como educador, «Nietzsche como educador» advertía, sin embargo, que, durante ese periodo, la Iglesia había mantenido «las fuerzas hostiles más o menos controladas $\mathrm{y}$, mediante la fuerte presión que ejercía, [conseguido] en cierta medida que entre ellas

11 La influencia de Nietzsche y Overbeck sobre la teología contemporánea y la relación de la Iglesia (protestante y católica) con el Imperio llegará hasta la polémica entre Erik Peterson y Carl Schmitt en el umbral del nacionalismo y la famosa «liquidación de la teología política». Véase Barbara Nichtweiss, Erik Peterson. Neue Sicht auf Leben und Werk, Friburgo: Herder, 1992, pp. 458-461, 727-830.

12 Véanse Franz Overbeck, Werke und Nachlaß, Metzler, Stuttgart, 1996 (Band 6.1: Christentum und Kultur, kritische Ausgabe des 1919 von C. A. Bernoulli kompilierten Nachlassmaterials) y 1999 (Band 7.2: Autobiographisches "Meine Freunde Treitschke, Nietzsche und Rohde”); Jacob Taubes, 'Entzauberung der Theologie: zu einem Porträt Overbecks', en Vom Kult zur Kultur. Bausteine zur einer Kritik der histörisches Vernunft, Münich: Wilhelm Fink, 1996, pp. 182-198, y Jacob Burckhardt, Weltgeschichtliche Betrachtungen [1905], Mit einem Nachwort von Jürgen Osterhammel, Múnich: C. H. Beck, 2018, pp. 167-216. 
hubiera asimilación mutua» (OC I 769). Que la Iglesia hubiera asumido en la Edad Media la tarea de asimilar entre sí [einander assimilirt] fuerzas hostiles y que esa tarea hubiera de asumirla ahora el Estado -el Imperio alemán-, para el que Nietzsche aún reservaría una mirada suspicaz, hacía de «Nietzsche como educador» un «lector residual» de Gibbon, para quien la Iglesia solo había podido asumir esa tarea en ausencia de una filosofía auténticamente política, es decir, solo por el debilitamiento de la filosofía política platónica como «platonismo»y «cristianismo»: mientras que, por un lado, los obispos occidentales necesitaron aumentar su capacidad de argumentación para oponerse al arrianismo y sobreponerse al establecimiento del cristianismo como religión oficial, por el otro los filósofos paganos acabaron convertidos en professores imperiales. Pero no es que la Iglesia asimilara fuerzas hostiles, sino que ella misma era una de esas fuerzas y solo por su hostilidad al Imperio mantuvo una tensión a la que el Imperio mismo respondería con la misma intensidad. Overbeck y Burckhardt, que leyeron a Gibbon con mucha más atención que Nietzsche al mantenerse escrupulosamente en sus oficios respectivos, comprendieron que, con la Iglesia, el cristianismo primitivo se enfrentaba a un peligro mayor para su propia esencia como ejercicio de una fe pura en un mundo que no podía desmoronarse, y que no era de ningún modo este mundo, que la amenaza que la Iglesia suponía para el Imperio: los grandes obispos orientales hasta Nicea y los obispos occidentales hasta san Agustín -con Atanasio en el centro, como Gibbon había dispuesto casi de un modo esotérico en las notas finales de su obra- aún podían ser acreedores a una filosofía entendida como educación y opuesta a cualquier época, intempestiva por definición; pero los filósofos paganos que entraron al servicio del Imperio tras la salida en falso de la constitución de los Antoninos (el punto de partida de la Declinación y caída de Gibbon) solo podían reclamar para sí la vieja aspiración sofística de una voluntad de poder. ${ }^{13}$

En un terreno estrictamente filológico, a diferencia de la teología de Overbeck y la historiografía de Burckhardt, el joven Erwin Rohde -la «sombra» del «caminante» Nietzsche- pudo haber visto que las enseñanzas de Nietzsche eran las mismas enseñanzas de la Segunda Sofística que él mismo había devuelto al primer plano de la época. El tercer capítulo de su libro sobre Der griechische Roman und seine Vorläufer (La novela griega y sus precursores), publicado en $1876 \mathrm{y}$ del que no hay apenas un comentario digno

13 Véase Andreas Urs Sommer, 〈Restgibbonianismus. Nietzsche und Gibbon〉, en Cord-Friedrich Berghahn y Till Kinzel, Edward Gibbon im deutschen Sprachraum. Bausteine einer Rezeptionsgeschichte, Heildelberg: Universitätsverlag Winter, 2015, pp. 359-380. Para la transformación del sofista en professor durante el Imperio romano, véase Werner Jaeger, Paideia. Die Formung des griechischen Menschen, Berlín: Walter de Gruyter, 1973, p. 1277, n. 17. Léase, con esta perspectiva, ¿Una mirada al Estado〉 en Humano, demasiado humano 1.8 (OC III 225-242). 
de ese nombre en la correspondencia con Nietzsche, dedicado a «la sofística griega de la época imperial», apenas roza el asunto de la relación entre los sofistas y los emperadores y se centra, por el contrario, en la diferencia de estilo entre «aticistas» y «asiáticos» (los griegos y cristianos de Nietzsche) en medio de un mundo romanizado. No deja de ser una ironía de la «filología del futuro» que solo ese aspecto estilístico resultara controvertido en la época del Segundo Imperio y que en 1900, el año de la muerte de Nietzsche, Ulrich von Wilamowitz-Moellendorf volviera a zanjar una polémica que había tenido a Nietzsche (en el trasfondo) y a Rohde como interlocutores. En Psyche (18901894), su obra maestra, publicada en los años de oscuridad de Nietzsche, Rohde omitiría toda mención del nombre de su amigo. ${ }^{14}$

Para entonces ya había empezado la lectura póstuma de Nietzsche, modulada por las falsificaciones editoriales del Archivo basadas, en última instancia, en una sola intuición: voluntad de poder y nada más. Podríamos preguntarnos cuáles son, más de un siglo después -si ha pasado el tiempo suficiente como para que un mundo y sus conceptos falsos se desmoronen-, las enseñanzas de «Nietzsche como educador» que, con el éxito de la aversión al platonismo y la maldición sobre el cristianismo, con el despliegue de la historia completa del nihilismo europeo, no hubieran podido susurrarle al oído los profesores del siglo II a los emperadores, preparando el cambio de mentalidad de los siglos III y IV, y no puedan seguir haciéndolo hoy. La cultura de los sofistas ha sido siempre una cultura de realistas (OC IV 687). ${ }^{15}$

14 Véase Alan Cardew, 〈The Dioscuri: Nietzsche and Erwin Rohde〉, Paul Bishop, Boydell y Brewer Nietzsche and Antiquity. His Reaction and Response to the Classical Tradition, Cambridge, 2013, pp. 458-478, y Barbara E. Borg, Paideia: The World of the Second Sophistic, Berlín: Walter de Gruyter, 2004.

15 Quiero agradecer a Francisco Arenas Dolz, Juan Diego González Sanz, Fernando Vidagany y Roberto Vivero que hayan leído estas páginas y me hayan hecho comentarios muy valiosos para mí. La comunicación entre amigos me sigue pareciendo esencial para cualquier sentido de la filosofía. Los errores de interpretación que queden son enteramente míos. 